Check for updates

Cite this: RSC Adv., 2018, 8, 2958

Received 19th December 2017 Accepted 25th December 2017

DOI: $10.1039 / c 7 r a 13441 j$

rsc.li/rsc-advances

\section{Assembly of $\mathrm{Na}_{3} \mathrm{~V}_{2}\left(\mathrm{PO}_{4}\right)_{2} \mathrm{~F}_{3} \mathrm{OC}$ nanoparticles in reduced graphene oxide enabling superior $\mathrm{Na}^{+}$ storage for symmetric sodium batteries $\uparrow$}

\begin{abstract}
Ye Yao, Lu Zhang, Yu Gao, * Gang Chen, Chunzhong Wang and Fei Du (DD*
Reduced graphene oxide ( $\mathrm{rGO}$ ) was used to encapsulate $\mathrm{Na}_{3} \mathrm{~V}_{2}\left(\mathrm{PO}_{4}\right)_{2} \mathrm{~F}_{3}$ @Carbon nanoparticles to overcome its inherent low electronic conductivity and achieve superior sodium storage performance. This as-prepared cathode delivers a remarkable rate performance with a discharge capacity of ca. $64 \mathrm{~mA} \mathrm{~h} \mathrm{~g}^{-1}$ at $70 \mathrm{C}$ and an ultra-long-term cyclability over 4000 cycles with great capacity retention of $81 \%$ at $30 \mathrm{C}$. This excellent performance can be attributed to the favorable combination of fast ionic conductivity of the NASICON structure and the interpenetrating conductive carbon framework; thus bringing a good pseudocapacitive quality to this material. Furthermore, thanks to the good sodium storage properties at low potential, a symmetric full cell can be assembled using $\mathrm{Na}_{3} \mathrm{~V}_{2}\left(\mathrm{PO}_{4}\right)_{2} \mathrm{~F}_{3} \mathrm{QC}$ (arGO as both cathode and anode. The full cell delivers a high discharge capacity of $53 \mathrm{~mA} \mathrm{~h} \mathrm{~g} \mathrm{~g}^{-1}$ at $20 \mathrm{C}$ rate, further demonstrating the feasibility of this hybrid material for smart grids.
\end{abstract}

\section{Introduction}

In recent years, sodium-ion batteries (SIBs) have gained worldwide interest as one of the most promising alternatives to lithium-ion batteries (LIBs) owing to their unique merits, including abundant resources, low cost of sodium-containing materials and an identical working principle to LIBs. ${ }^{1-6}$ However, much effort still should be devoted to the exploration of novel electrode materials because the larger ionic radius of $\mathrm{Na}^{+}$usually induces sluggish kinetics during the electrochemical insertion reactions with unsatisfactory rate capability and cycle stability. ${ }^{7-12}$

NASICON-type $\left(\mathrm{Na}^{+}\right.$super-ionic conductor) phosphates are characteristics as the robust three-dimensional open frameworks facilitating fast ionic transportation. ${ }^{8,13}$ Among various NASICON type materials, sodium-vanadium fluorophosphates, $\mathrm{Na}_{3} \mathrm{~V}_{2}\left(\mathrm{PO}_{4}\right)_{2} \mathrm{~F}_{3}$ attracts particular attention because of the high theoretical energy density of $475 \mathrm{~W} \mathrm{~h} \mathrm{~kg}{ }^{-1}$, approaching that of $\mathrm{LiFePO}_{4}\left(530 \mathrm{~W} \mathrm{~h} \mathrm{~kg}{ }^{-1}\right)$ in LIBs. ${ }^{14-18}$ Unfortunately, its low electronic conductivity of $10-12 \mathrm{~S} \mathrm{~cm}^{-1}$ limits the synergic transfer between the electrons and ions; thus the high theoretical capacity can hardly be achieved. ${ }^{18,19}$ To improve the sodium storage performance, the popular strategy is the preparation of nanocomposite materials with various carbonaceous materials, like CNT, amorphous carbon, and etc. ${ }^{20-23}$ On one

Key Laboratory of Physics and Technology for Advanced Batteries (Ministry of Education) State Key Laboratory of Superhard Materials, College of Physics, Jilin University, China.E-mail: dufei@jlu.edu.cn; gaoyu@jlu.edu.cn

$\dagger$ Electronic supplementary information (ESI) available. See DOI: $10.1039 / \mathrm{c} 7 \mathrm{ra} 13441 \mathrm{j}$ hand, carbonaceous materials can help to reduce the particle size and shorten the ionic transfer pathway; ${ }^{19,24}$ on the other, the high conductivity of working electrode is greatly improved, facilitating fast electronic transportation. ${ }^{23,25}$ Besides the abovementioned methods, pseudocapacitive charge storage, which is governed by surface or near-surface reversible redox reaction, is also another effective way to realize high-rate charge-discharge behavior. ${ }^{14,26,27}$ It has been demonstrated that pseudocapacity can bring in well balance in the energy and power density of the electrode materials. Though many nanosized anode materials, including $\mathrm{Nb}_{2} \mathrm{O}_{5},{ }^{28} \mathrm{RuO}_{2}$ (ref. 29) and etc. has exhibited enhanced pseudocapacitive contribution, there is a great challenge to exploit the intercalation pseudocapacity in the positive side.

In this work, we synthesized NVPF nanoparticles embedded in the reduced graphene oxide ( $\mathrm{rGO}$ ) by a nanocasting technique to realize a high-rate charge-discharge ability. ${ }^{25,30}$ Thanks to the improved electronic conductivity and enhanced pseudocapacitive charge storage, the NVPF@C@rGO hybrid electrode demonstrated a superior rate capability with a discharge capacity of $64 \mathrm{~mA} \mathrm{~h} \mathrm{~g}^{-1}$ at 70C rate and ultralong cycle life over 4000 cycles with a capacity retention of $81 \%$ at $30 \mathrm{C}$ rate. In addition, a symmetric cell based on NVPF@C@rGO as both cathode and anode was assembled successfully, which showed a high reversible capacity of $107 \mathrm{~mA} \mathrm{~h} \mathrm{~g}^{-1}$ at $1 \mathrm{C}$ and $53 \mathrm{~mA} \mathrm{~h} \mathrm{~g}^{-1}$ at $20 \mathrm{C}$ indicative of the promising application in the grid energy storage.

\section{Results and discussion}

The XRD patterns of NVPF@C@rGO and NVPF@C are compared in Fig. 1a, with no observed second phases. All the 
(a)

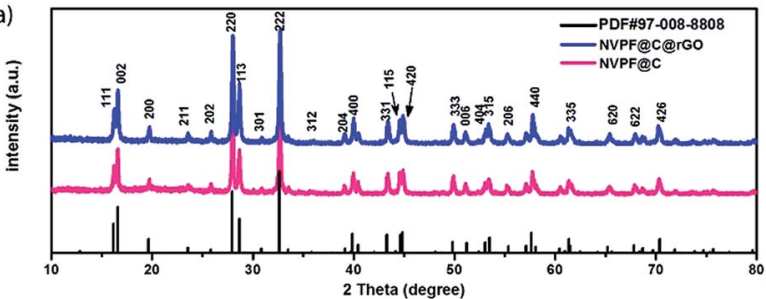

(b)

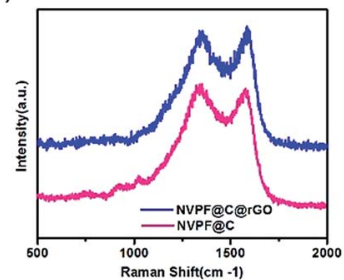

(d)

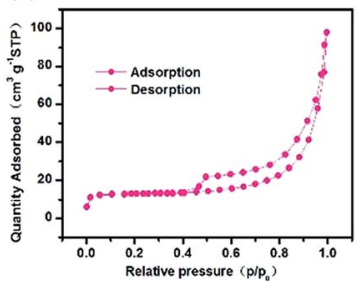

(c)

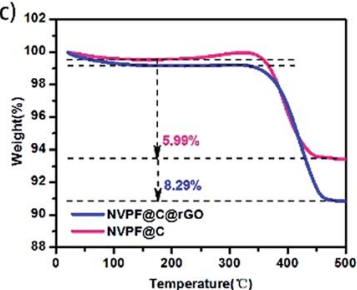

(e)

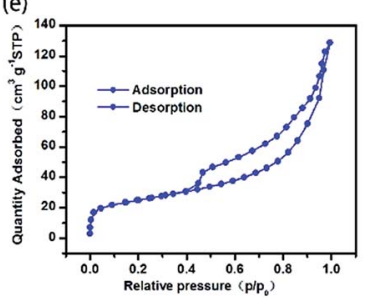

Fig. 1 X-ray diffraction pattern of the pristine NVPFaCarGO and NVPF@C nanocomposites (a); Raman spectrum of NVPF@CarGO (b); thermogravimetric measurement (TG) profile of the pristine NVPFaC@rGO and NVPF@C nanocomposites(c); nitrogen adsorption-desorption isotherms of NVPFaC (d) and NVPFaCarGO (e).

diffraction peaks can be indexed based on the tetragonal symmetry with the space group of $P 42 / \mathrm{mnm}$ and the lattice parameters are calculated and listed in Table S1. $\dagger$ The introduced carbon was further confirmed by Raman spectroscopy as displayed in Fig. 1b. Two typical Raman peaks are identified at $\sim 1342$ and $\sim 1588 \mathrm{~cm}^{-1}$, corresponding to $\mathrm{D}$ and $\mathrm{G}$ bands, respectively. The relative intensity ratio $\left(I_{\mathrm{D}} / I_{\mathrm{G}}\right)$ is usually used as a criterion to evaluate the degree of disorder and defects in carbonaceous materials. ${ }^{31}$ After introducing rGO, the $I_{\mathrm{D}} / I_{\mathrm{G}}$ decreased from 1.027 (NVPF@C) to 0.960 (NVPF@C@rGO), suggesting the lower degree of disorder and a better crystallinity of carbon. Quantitatively, TG measurement was used to estimate the content of carbon in the pristine nanocomposite. As shown in Fig. 1c, the contents of carbon for the NVPF@C and NVPF@C@rGO samples were ca. $5.99 \mathrm{wt} \%$ and $8.29 \mathrm{wt} \%$, respectively. Therefore, the content of rGO is $2.3 \%$. The nitrogen adsorption-desorption isothermal technique was further employed to examine detailed micro-structural information. After compositing with rGO (Fig. 1d and e), NVPF@C@rGO hybrid exhibits a larger BET surface are a $\left(86 \mathrm{~m}^{2}\right.$ $\left.\mathrm{g}^{-1}\right)$ in compare with the value of NVPF@C $\left(41 \mathrm{~m}^{2} \mathrm{~g}^{-1}\right)$, because of the layer characteristic of rGO. Higher BET surface area might increase a larger electrolyte-electrode contact area for better sodium storage performance.

Morphological features of two samples were observed by SEM and TEM. It can be seen that NVPF nanoparticles with tens to hundreds of nanometers in size are wrapped by the flexible

rGO nanosheets (Fig. 2a). TEM image (Fig. 2b and c) not only confirms the morphologic features of SEM, but also indicates a thin carbon layer (3-4 nm) is coated on the surface of NVPF particles. This hierarchical carbon coating structure is helpful to limit the growth of NVPF particles and act as an effective electronic transfer network. HRTEM images (Fig. 2c) clearly suggest a lattice fringes of $0.344 \mathrm{~nm}$, corresponding to 202 plane of tetragonal NVPF. In contrast, NVPF@C displays an agglomerated nanoparticles wrapped in the amorphous carbon matrix with non-uniformly dispersed particle size ranging from 200 to $500 \mathrm{~nm}$, as displayed in Fig. S1. $\dagger$ In addition, the element mappings (Fig. 2d-h) demonstrated a uniform distribution of various elements (Na, V, P, F and C) in the NVPF@C@rGO nanocomposite.

The electrochemical properties of NVPF@C@rGO and NVPF@C were evaluated using coin-type cells with sodium metal as the counter electrode. Fig. 3a shows the represented galvanostatic charge-discharge profiles of NVPF@C@rGO between 2.0 and $4.3 \mathrm{~V}$ at a current density of $0.5 \mathrm{C}$ rate, consistent with those profiles of NVPF@C (Fig. S2 $\dagger$ ). The initial charge capacity is obtained as $c a .127 \mathrm{~mA} \mathrm{~h} \mathrm{~g}^{-1}$, close to the theoretical capacity of NVPF (128 mA h g ${ }^{-1}$ ) when two $\mathrm{Na}^{+}$ions are extracted. Since the carbonaceous materials, including amorphous carbon and rGO, are only capable of accommodating sodium ions at low potential (below $1.0 \mathrm{~V}$ ) and their capacity contribution in the high voltage region of above $2.0 \mathrm{~V}$ is negligible. $^{32}$ Furthermore, NVPF@C@rGO demonstrates superior rate capability. As shown in Fig. 3b, the cathode delivers reversible capacities of $120,116,114,112,105,89,77,71$, and $64 \mathrm{~mA} \mathrm{~h} \mathrm{~g}^{-1}$ at current densities of 1, 3, 5, 10, 15, 20, 30, 50 and 70C, respectively. Particularly, when the current density returns

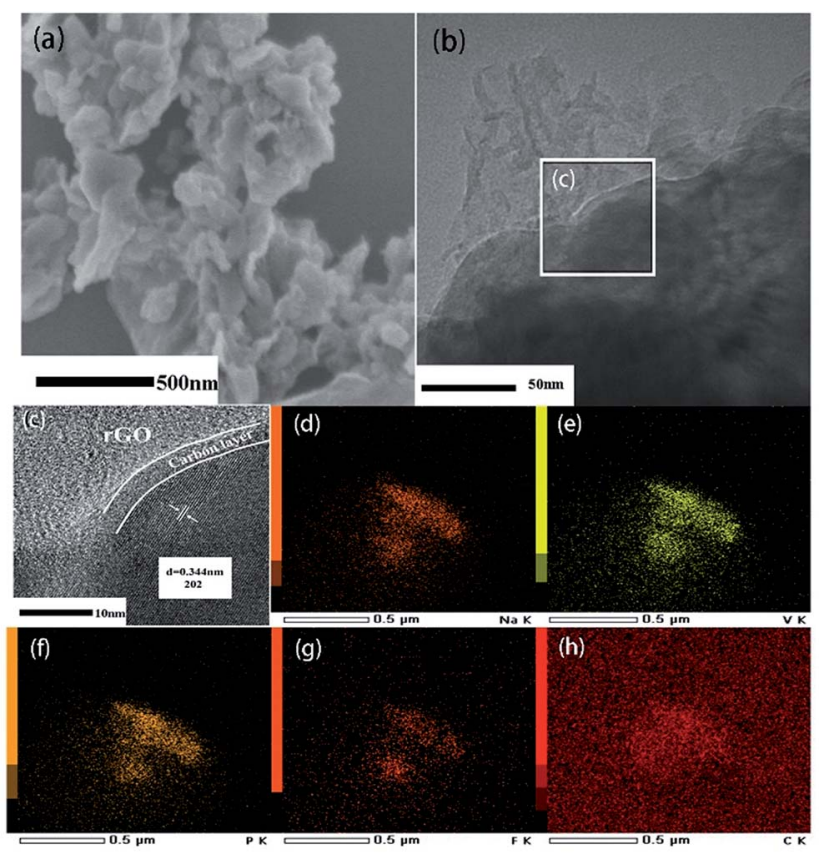

Fig. 2 SEM (a), TEM (b) and HRTEM (c) images of NVPFaC arGO; (d)(h) represents the HAADF-STEM image and elemental mapping of $\mathrm{Na}, \mathrm{V}, \mathrm{P}, \mathrm{F}$ and $\mathrm{C}$, respectively. 

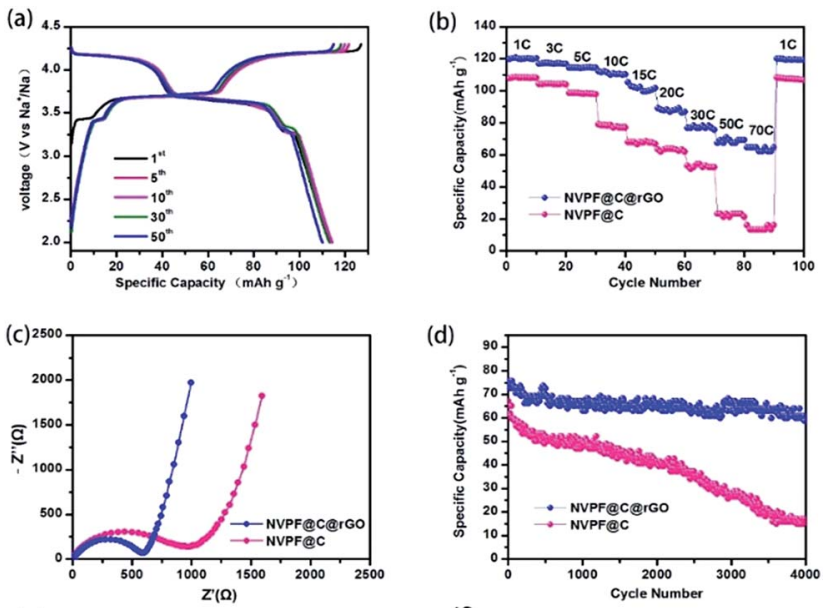

(d)
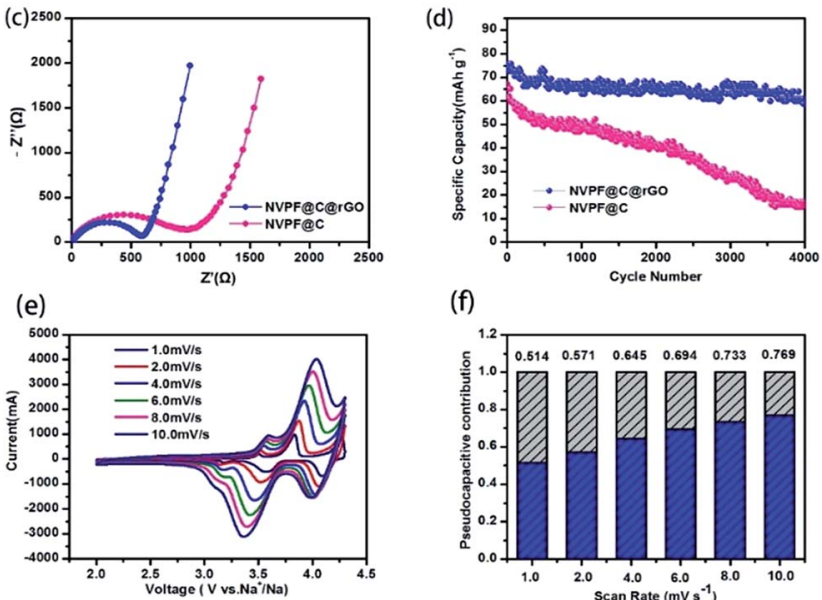

(f)

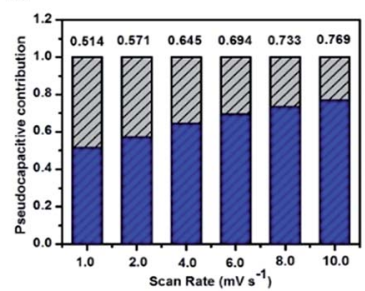

Fig. 3 Charge-discharge profiles of NVPF@C arGO at $0.5 \mathrm{C}$ rate (a); rate performances at various current densities (b), the Nyquist plots after the 50th cycles (c) of NVPFaC@arGO and NVPF@C; long-term cycle stability of the NVPF aC arGO and NVPF@C tested at 30C rate for 4000 cycles (d). CV curves of NVPFaC arGO at sweep rates from 1 to $10 \mathrm{mV} \mathrm{s}^{-1}(\mathrm{e})$; diagram of capacitive contribution to the total capacity (f).

to $1 \mathrm{C}$ after 100 cycles, the specific capacity is nearly recovered to the same extent as its initial ten cycles, indicative of an excellent reversibility even at high-rate charge-discharge. In contrast, the NVPF@C nanocomposite can sonly deliver $16 \mathrm{~mA} \mathrm{~h} \mathrm{~g}^{-1}$ at 70C rate, much lower than that of NVPF@C@rGO. To elucidate the reason for the enhanced rate performance after compositing with rGO, EIS is recorded and displayed in Fig. 3c. Both EIS curves are composed of a semicircle in the high frequency and medium frequency region.

Characteristic of the charge-transfer reaction and one straight line in the low frequency region reflecting the sodiumdiffusion process in the bulk phase. ${ }^{33,34}$ After quantitative fitting of the impedance spectra using the equivalent circuit (Fig. S3 $\dagger$ ), the charge-transfer resistance $\left(R_{\mathrm{ct}}\right)$ of NVPF@C@rGO cell are calculated to be $561.1 \Omega$, lower than that value of NVPF@C $(811.2 \Omega)$ at the same electrochemical stages. The decrease in the $R_{\text {ct }}$ might be related to the hierarchical architecture design with carbon coated NVPF wrapped in rGO nanosheets; thus accelerating electronic and ionic transfer of the working electrode. ${ }^{35}$ The inclined line in the low frequency region represents the Warburg impedance, which is associated with the $\mathrm{Na}^{+}$ion diffusion in the NVPF particles. The apparent diffusion coefficient of $\mathrm{Na}^{+}, D_{\mathrm{Na}}$, can be calculated by the equation ${ }^{36}$

$$
D_{\mathrm{Na}}=\frac{0.5 R^{2} T^{2}}{S^{2} n^{4} F^{4} C^{2} \sigma^{2}}
$$

In this equation, $R$ is the gas constant, $T$ the absolute temperature, $F$ the Faraday constant; and $\sigma$ is the Warburg factor which obeys the following relationship:

$$
Z^{\prime}=R_{\mathrm{S}}+R_{\mathrm{CT}}+\sigma \omega^{-1 / 2}
$$

Fig. S4 $\uparrow$ displays the linear fitting of $Z^{\prime} v s . \omega^{-1 / 2}$, from which the slope $\sigma$ can be obtained. The sodium diffusion coefficients of NVPF@C and NVPF@C@rGO are $1.32 \times 10^{-13}$ and $3.08 \times$ $10^{-12}$, respectively. The slightly improved diffusion coefficient maybe because the increase of conductivity, which related to rGO. Inspired by the outstanding rate performance, the longterm cycle stability of NVPF@C@rGO and NVPF@C was also examined (Fig. 3d). The hybrid electrode delivers a discharge capacity of $60.8 \mathrm{~mA} \mathrm{~h} \mathrm{~g}{ }^{-1}$ after 4000 cycles at 30C, corresponding to $81 \%$ of its initial capacity. In sharp contrast, NVPF@C could only deliver a low discharge capacity of $14.9 \mathrm{~mA} \mathrm{~h} \mathrm{~g}^{-1}$ after 4000 cycles.

To further understand the superior rate capability of NVPF@C@rGO hybrid electrode, the kinetic properties are investigated by cyclic voltammetry $(\mathrm{CV})$ at various scanning rates. Fig. 3e shows the $\mathrm{CV}$ curves at sweep rates of $1 \mathrm{mV} \mathrm{s}^{-1}$ to $10 \mathrm{mV} \mathrm{s}^{-1}$. There are three redox couples corresponding to the three symmetrical working plateaus observed at ca. 3.3, 3.6 and $4.1 \mathrm{~V}$ in both charge and discharge profiles. The first two redox couples can be attributed to a two-step process insertion into/ extraction of $\mathrm{Na}^{+}$from $\mathrm{Na}(2)$ sites, while the higher potential at around $4.2 \mathrm{~V}$ is derive from the $\mathrm{Na}(1)$ sites. ${ }^{19,37}$ The redox peaks deviated from the equilibrium position due to the larger polarization under the higher sweeping speed. Relationships between the peak currents and scan rates in logarithmic format indicated the type of electrochemical behaviour. Generally, the slope of 0.5 indicates a diffusion-controlled behaviour, whereas the 1.0 represents a surface diffusion process, the slope values of second pairs of peaks were calculated to 0.61 and 0.79 , indicating a pseudocapacitive process between typical behaviours of batteries and capacitors. ${ }^{\mathbf{3 8 - 4 0}}$ The total capacitive contribution at a certain scan rate could be quantified by separating as combination of surface capacitive effects and diffusion-controlled process according to ${ }^{39}$

$$
i(V)=k_{1} V+k_{2} V^{1 / 2}
$$

where $k_{1}$ and $k_{2}$ are constants for a given potential. Quantitative calculation results (Fig. 3f) reveal that the value of capacitive contribution at scan rate of $1 \mathrm{mV} \mathrm{s}^{-1}$ is $51 \%$, and gradually increases as the scan rate increases, finally reached to $77 \%$ at $10 \mathrm{mV} \mathrm{s}^{-1}$. All redox peaks are broadened at high sweep rates, which conforms the capacitive behaviour at high rates.

Moreover, a symmetric SIBs full cell is assembled configured $\left[\mathrm{Na}_{3} \mathrm{~V}_{2}\left(\mathrm{PO}_{4}\right)_{2} \mathrm{~F}_{3}\right.$ @C@rGO $\| 1 \mathrm{M} \mathrm{NaClO}_{4}$ in (EC : $\left.\mathrm{PC}=1: 1\right) \| \mathrm{Na}_{3}-$ $\mathrm{V}_{2}\left(\mathrm{PO}_{4}\right)_{2} \mathrm{~F}_{3} @ \mathrm{C} @ \mathrm{rGO}$. Before investigating the electrochemical performance of the full cell, the $\mathrm{CV}$ profiles (Fig. 4a) of NVPF@C@rGO in both cathode and anode are evaluated. NVPF@C@rGO demonstrates a working plateau at ca.1.4 Vvs. $\mathrm{Na}^{+} / \mathrm{Na}$ when being discharged to $0.01 \mathrm{~V}$ with discharge capacity of $95 \mathrm{~mA} \mathrm{~h} \mathrm{~g}{ }^{-1}$ (Fig. S5†). The mass balance between the 
(a)
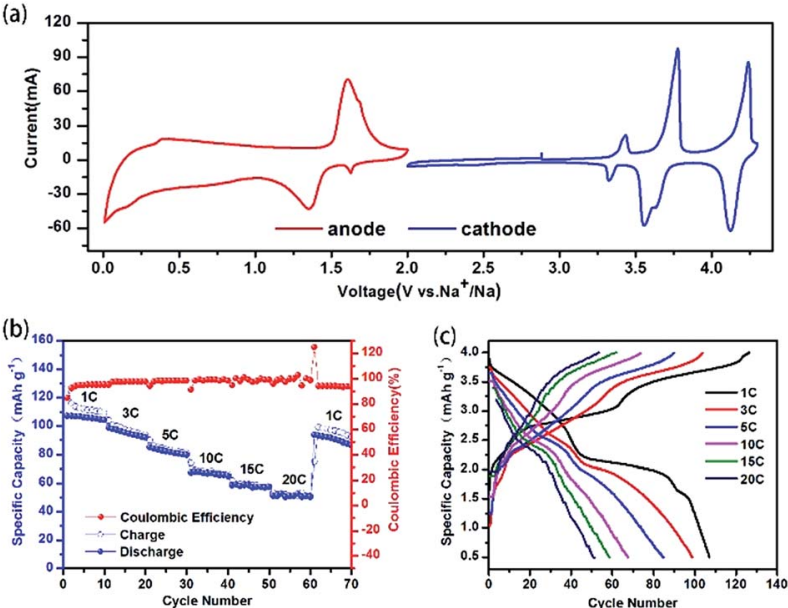

(d)

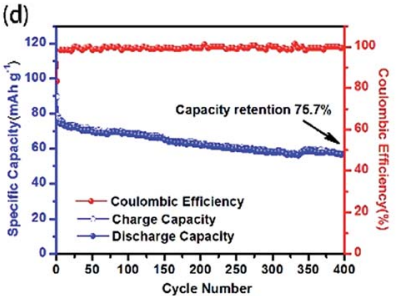

(e)

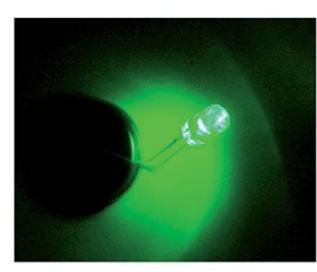

Fig. 4 Electrochemical properties of NVPFaCarGO as symmetrical full cell material. Cyclic voltammetry curves of NVPFaC@rGO as cathode and anode (a); rate performances (b) and charge-discharge profiles at various current densities (c) of the NVPFaCarGO symmetrical full cell; the cycling performance of the NVPF@C@rGO symmetrical full cell at $10 \mathrm{C}$ (d); the lighted LED bulbs driven by the full cell (e).

cathode and anode is fixed as $1: 1.3$ to ensure the full activation of NVPF during the initial charging process and improve the initial coulombic efficiency of the symmetric cell. Fig. 4b evaluates the rate capability for every ten successive cycle. A high discharge capacity of $107 \mathrm{~mA} \mathrm{~h} \mathrm{~g}^{-1}$ is delivered at $1 \mathrm{C}$ rate and $53 \mathrm{~mA} \mathrm{~h} \mathrm{~g}{ }^{-1}$ for 20C. As increased in the $\mathrm{C}$ rate, the working plateaus in the charge-discharge profiles disappears gradually owing to the enhanced polarization (Fig. 4c). The cycle stability are also recorded for 400 cycles at Fig. $4 \mathrm{~d}$ with capacity retention of $75.7 \%$ at $10 \mathrm{C}$. Furthermore, LED lamp could be lit successfully by this full cell after 25th charge-discharge cycle at $1 \mathrm{C}$ (Fig. S6 $\dagger$ and 4e), suggesting great practical prospect.

\section{Experimental}

\section{Synthetic procedures}

The main paragraph text follows directly on here. Graphene oxide (GO) was prepared according to Hummers method. ${ }^{41}$ To prepare the NVPF@C@rGO nanocomposite, $0.2 \mathrm{mmol}$ $\mathrm{NH}_{4} \mathrm{VO}_{3}, 0.3 \mathrm{mmol} \mathrm{NaF}$, and $0.2 \mathrm{mmol} \mathrm{NH}_{4} \mathrm{H}_{2} \mathrm{PO}_{4}$ powders were first dissolved in deionized water. Citric acid ( $0.29 \mathrm{~g})$ was then added and constantly stirred at room temperature for 12 hours. Second, $0.042 \mathrm{~g}$ GO and $42 \mathrm{ml}$ deionized water were ultrasonically treated for 2 hours to form a uniform dispersion, and then added into the above solution with stirring at

room temperature for another 12 hours. Third, the mixed solution was quick freezed with liquid nitrogen then freezedrying at $-40{ }^{\circ} \mathrm{C}$ for $48 \mathrm{~h}$ to slowly evaporate the solvent. Finally, the precursor powder sample was acquired after a twostep heat treatment: $300{ }^{\circ} \mathrm{C}$ for 4 hours and then $650{ }^{\circ} \mathrm{C}$ for 8 hours under a nitrogen atmosphere to crystallize NVPF and reduce GO. In contrast, NVPF@C nanocomposite was prepared following the identical procedure of NVPF@C@rGO without adding rGO.

\section{Materials and methods}

The phase purity of the obtained samples was examined by Xray diffraction (XRD; RigaKu D/max-2550) with $\mathrm{Cu} \mathrm{K} \alpha$ source in the $2 \theta$ range of $10-80^{\circ}$ at a scanning rate of $2^{\circ} \mathrm{min}^{-1}$. The morphological features were observed by a Hitachi SU8020 scanning electron microscope (SEM) and a FEI Tecnai G2 transmission electron microscope (TEM). Raman spectroscopy was recorded on a Renishaw in via Raman spectroscopy with Ar-ion laser excitation $(\lambda=514.5 \mathrm{~nm})$. Quantitatively, the content of carbon was evaluated using a Mettler-Toledo Thermogravimetric (TG) analyzer. Nitrogen adsorptiondesorption isotherms were measured at $77 \mathrm{~K}$ using a Micromeritics ASAP 2010 instrument. The specific surface area was calculated using the Brunauer-Emmett-Teller (BET) method and the pore-size distribution (PSD) curves were calculated from the isotherm using the Barrett-Joyner-Halenda (BJH) algorithm.

\section{Electrochemical measurements}

Electrochemical experiments were carried out using 2032-type coin cells. A typical electrode was composed of $70 \mathrm{wt} \%$ active material, $20 \mathrm{wt} \%$ super $\mathrm{P}$ conductive additive, and $10 \mathrm{wt} \%$ polyvinylidene fluoride binder (PVDF) dissolved in $\mathrm{N}$-methylpyrrolidone (NMP). The obtained slurry mixture was pasted onto aluminium foil and then dried at $120{ }^{\circ} \mathrm{C}$ for $12 \mathrm{~h}$ in a vacuum oven. After dividing the electrode film into square parts of $0.8 \times 0.8 \mathrm{~cm}^{2}$, coin cells were assembled in a glove box $\left(\mathrm{O}_{2} \leq 0.1 \mathrm{ppm}, \mathrm{H}_{2} \mathrm{O} \leq 0.1 \mathrm{ppm}\right)$. The loading mass of the active material in each coin cell is typically $1.2-1.5 \mathrm{mg} \mathrm{cm}^{-2}$. The cathode and anode electrodes were separated by a glass fiber filter (Whatman GF/C). The electrolyte was $1 \mathrm{M} \mathrm{NaClO}_{4}$ dissolved in a solvent of ethylene carbonate (EC) and propylene carbonate (PC) $(1: 1 \mathrm{v} / \mathrm{v})$ and $5 \%$ fluoroethylene carbonate (FEC). Galvanostatic charge-discharge tests were carried out at a voltage window of $2.0-4.3 \mathrm{~V}$ on a Land-2001A (Wuhan, China) automatic battery tester at room temperature. Here, $\mathrm{C}$ rate was used to characterize the current rate; $1 \mathrm{C}$ equaled $128 \mathrm{~mA} \mathrm{~g}^{-1}$. The specific capacity was calculated on the basis of the active cathode material after subtracting the carbon content. Data of cyclic voltammetry $(\mathrm{CV})$ and electrochemical impedance spectra (EIS) were recorded on a VSP multichannel potentiostatic-galvanostatic system (Bio-logic, France). The test conditions of EIS were in the frequency range from $1 \mathrm{MHz}$ to $1 \mathrm{mHz}$ with an ac voltage of $5 \mathrm{mV}$. 


\section{Conclusions}

NVPF@C@rGO nanocomposite was successfully synthesized by the nanocasting technique, where carbon-coated NVPF nanoparticles were wrapped by rGO nanosheets. Owing to the enhanced kinetics properties, NVPF@C@rGO hybrid electrode demonstrates a superior sodium storage performance in comparison with NVPF@C material. By analyzing the DSCV, a strong pseudocapacitive contribution is found which well explains the high-rate charge-discharge ability. The symmetrical cell with NVPF@C@rGO as both cathode and anode was, for the first time, constructed, further demonstrating the feasibility of NVPF@C@rGO nanocomposite in SIBs.

\section{Conflicts of interest}

There are no conflicts to declare.

\section{Acknowledgements}

This work was financially supported by funding from "973" project (2015CB251103), NSFC (51572107) and joint foundation between Jilin Province and Jilin University (SXGJQY2017-10).

\section{References}

1 N. Yabuuchi, K. Kubota, M. Dahbi and S. Komaba, Chem. Rev., 2014, 114, 11636.

2 X. Xiang, K. Zhang and J. Chen, Adv. Mater., 2015, 27, 5343.

3 N. Yabuuchi, M. Kajiyama, J. Iwatate, H. Nishikawa, S. Hitomi, R. Okuyama, R. Usui, Y. Yamada and S. Komaba, Nat. Mater., 2012, 11, 512.

4 Z. Wen, Y. Hu, X. Wu, J. Han and Z. Gu, Adv. Funct. Mater., 2013, 23, 1005.

5 Y. Li, Y. Hu, X. Qi, X. Rong, H. Li, X. Huang and L. Chen, Energy Storage Materials, 2016, 5, 191.

6 L. Wang, Y. Lu, J. Liu, M. Xu, J. Cheng, D. Zhang and J. B. Goodenough, Angew. Chem., Int. Ed., 2013, 52, 1964.

7 K. Saravanan, C. W. Mason, A. Rudola, K. H. Wong and P. Balaya, Adv. Energy Mater., 2013, 3, 444.

8 Y. Xu, Q. Wei, C. Xu, Q. Li, Q. An, P. Zhang, J. Sheng, L. Zhou and L. Mai, Adv. Energy Mater., 2016, 6, 1600389.

9 X. Rui, W. Sun, C. Wu, Y. Yu and Q. Yan, Adv. Mater., 2015, 27, 6670 .

10 Z. Dai, U. Mani, H. T. Tan and Q. Yan, Small Methods, 2017, 1, 1700098.

11 N.-W. Li, Y.-X. Yin, S. Xin, J.-Y. Li and Y.-G. Guo, Small Methods, 2017, 1, 1700094.

12 C. Zhao, Y. Lu, Y. Li, L. Jiang, X. Rong, Y.-S. Hu, H. Li and L. Chen, Small Methods, 2017, 1, 1600063.

13 D. Kundu, E. Talaie, V. Duffort and L. F. Nazar, Angew. Chem., Int. Ed., 2015, 54, 3431.

14 X. Xiang, Q. Lu, M. Han and J. Chen, Chem. Commun., 2016, 52, 3653.

15 P. Serras, V. Palomares, P. Kubiak, L. Lezama and T. Rojo, Electrochem. Commun., 2013, 34, 344.
16 H. Jin, J. Dong, E. Uchaker, Q. Zhang, X. Zhou, S. Hou, J. Li and G. Cao, J. Mater. Chem. A, 2015, 3, 17563.

17 M. Peng, B. Li, H. Yan, D. Zhang, X. Wang, D. Xia and G. Guo, Angew. Chem., Int. Ed., 2015, 54, 6452.

18 Q. Liu, X. Meng, Z. Wei, D. Wang, Y. Gao, Y. Wei, F. Du and G. Chen, ACS Appl. Mater. Interfaces, 2016, 8, 31709.

19 Q. Liu, D. Wang, X. Yang, N. Chen, C. Wang, X. Bie, Y. Wei, G. Chen and F. Du, J. Mater. Chem. A, 2015, 3, 21478.

20 G. Li, D. Jiang, H. Wang, X. Lan, H. Zhong and Y. Jiang, J. Power Sources, 2014, 265, 325.

21 Y. Fang, L. Xiao, X. Ai, Y. Cao and H. Yang, Adv. Mater., 2015, 27, 5895.

22 S. Chen, C. Wu, L. Shen, C. Zhu, Y. Huang, K. Xi, J. Maier and Y. Yu, Adv. Mater, 2017, 1700431.

23 J. Liu, K. Tang, K. Song, P. A. van Aken, Y. Yu and J. Maier, Nanoscale, 2014, 6, 5081.

24 L. Zhang, H. Xiang, Z. Li and H. Wang, J. Power Sources, 2012, 203, 121.

25 Y. H. Jung, C. H. Lim and D. K. Kim, J. Mater. Chem. A, 2013, $1,11350$.

26 Z. Jian, V. Raju, Z. Li, Z. Xing, Y. Hu and X. Ji, Adv. Funct. Mater., 2015, 25, 5778.

27 Z. Wei, X. Meng, Y. Yao, Q. Liu, C. Wang, Y. Wei, F. Du and G. Chen, ACS Appl. Mater. Interfaces, 2016, 8, 35336.

28 V. Augustyn, J. Come, M. A. Lowe, J. W. Kim, P. L. Taberna, S. H. Tolbert, H. D. Abruna, P. Simon and B. Dunn, Nat. Mater., 2013, 12, 518-522.

29 J. P. Zheng, P. J. Cygan and T. R. Jow, J. Electrochem. Soc., 1995, 142(8), 2699.

30 X. Rui, W. Sun, C. Wu, Y. Yu and Q. Yan, Adv. Mater., 2015, 27(42), 6670.

31 W. Ren, Z. Zheng, C. Xu, C. Niu, Q. Wei, Q. An, K. Zhao, M. Yan, M. Qin and L. Mai, Nano Energy, 2016, 25, 145.

32 D. Wang, N. Chen, M. Li, C. Wang, H. Ehrenberg, X. Bie, Y. Wei, G. Chen and F. Du, J. Mater. Chem. A, 2015, 3, 8636. 33 Y. Jiang, Z. Yang, W. Li, L. Zeng, F. Pan, M. Wang, X. Wei, G. Hu, L. Gu and Y. Yu, Adv. Energy Mater., 2015, 5, 1402104.

34 S. Li, P. Ge, C. Zhang, W. Sun, H. Hou and X. Ji, J. Power Sources, 2017, 366, 249.

35 P. Ge, X. Cao, H. Hou, S. Li and X. Ji, ACS Appl. Mater. Interfaces, 2017, 9, 34979.

36 A. J. Bard and L. R. Faulkner, Electrochemical Methods: Fundamentals and Applications, Wiley, New York, 1980, p. 328.

37 W. Song, X. Ji, Z. Wu, Y. Yang, Z. Zhou, F. Li, Q. Chen and C. E. Banks, J. Power Sources, 2014, 256, 258.

38 H. Lindström, S. Södergen, A. Solbrand, H. Rensmo, J. Hjelm, A. Hagfeldt and S. Lindquist, J. Phys. Chem. B, 1997, 101, 7717.

39 J. Wang, J. Polleux, J. Lim and B. Dunn, J. Phys. Chem. C, 2007, 111, 14925.

40 P. Ge, H. Hou, X. Ji, Z. Huang, S. Li and L. Huang, Mater. Chem. Phys., 2017, 203, 185.

41 W. S. Hummers Jr and R. E. Offeman, J. Am. Chem. Soc., 1958, 80, 1339. 